\title{
Comparison of sampling techniques for Rift Valley Fever virus potential vectors, Aedes aegypti and Culex pipiens complex, in Ngorongoro District in northern Tanzania
}

\author{
CLEMENT N. MWEYA ${ }^{1,2, *}$ SHARADHULI I. KIMERA ${ }^{2}$, ESRON D. KARIMURIBO ${ }^{2}$ \& LEONARD E.G. MBOERA ${ }^{3}$ \\ ${ }^{1}$ National Institute for Medical Research, Tukuyu Research Centre, P.O. Box 538, Tukuyu, Tanzania \\ ${ }^{2}$ Sokoine University of Agriculture, Department of Veterinary Medicine and Public Health, P.O. Box 3021, Morogoro, \\ Tanzania \\ ${ }^{3}$ National Institute for Medical Research, Headquarters, P.O. Box 9653, Dar es Salaam, Tanzania
}

\begin{abstract}
We investigated mosquito sampling techniques with two types of traps and attractants at different time for trapping potential vectors for Rift Valley Fever virus. The study was conducted in six villages in Ngorongoro district in Tanzania from September to October 2012. A total of 1814 mosquitoes were collected, of which 738 were collected by CDC light traps and 1076 by Mosquito Magnet trapping technique. Of the collected mosquitoes, $12.46 \%(\mathrm{~N}=226)$ were Aedes aegypti and $87.54 \%(\mathrm{~N}=1588)$ were Culex pipiens complex. More mosquitoes were collected outdoors using Mosquito Magnets baited with octenol attractant, 36.38\% $(\mathrm{N}=660)$ followed by indoor trapping using CDC light traps without attractant, $29.60 \%(\mathrm{~N}=537)$. Most of Ae. aegypti mosquitoes were collected outdoor using Mosquito Magnets, 95\% ( $\mathrm{N}=214)$ whereas Cx. pipiens complex were trapped both indoor using CDC light traps without attractant and outdoors using both CDC light traps baited with carbon dioxide $\left(\mathrm{CO}_{2}\right)$ sachets and Mosquito Magnets. Analysis on the differences in abundance of mosquitoes trapped by different techniques using Generalized Linear Models was statistically significance at $\mathrm{p}$ value $<0.05$ for both species. Three hours mosquito collections show differing patterns in activity, most Ae. aegypti species were collected primarily during the first and last quarters of the day. Cx pipiens complex was active throughout the night, early evening and early morning then decreased markedly during the day time. The results presented in this paper emphasize the possibility of using Mosquito Magnets in order to efficiently capture these potential RVF vectors.
\end{abstract}

Keyword: Rift Valley Fever, Aedes aegypti, Culex pipiens, mosquito sampling, trap, Tanzania

\section{Introduction}

Rift Valley fever (RVF) is a mosquito-borne arboviral infection caused by a virus belonging to the Phlebovirus genus of the Bunyaviridae family (Daubney et al., 1931; Davies, 1975). The virus is passed from one generation of Aedes mosquito to another trans-ovarially (Logan et al., 1991; Diallo et al., 2000; Romoser et al., 2011). This accounts for the continued presence of the RVF virus in enzootic foci and provides the virus with a sustainable mechanism of existence as eggs which can survive for several years in dry conditions (Logan et al., 1991; Linthicum et al., 1999; Gerdes, 2002; Nguku et al., 2010). Known important RVF vectors in East Africa include Aedes mcintoshi, Ae. ochraeus, Ae. dalzieli and Ae. vexans (Logan et al., 1990; Turell et al., 2008; Sang et al., 2010).

Aedes aegypti has been found naturally infected with RVF virus in Sudan in 2007 and has the ability to transmit the virus both mechanically and biologically (EFSA, 2013). Laboratory established colonies of Ae. aegypti from Tahiti exhibited the highest disseminated infection rates of RVF virus when compared with other potential vectors in the Mediterranean (Moutailler et al., 2008). Ae. aegypti has also demonstrated infection and transmission rates of the non-structural NSs protein deletion virus similar to wild type virus while dissemination rates were significantly reduced (Crabtree et al., 2012). Culex pipiens has been incriminated as the main RVF vector in Egypt (Meegan

* Correspondence: Clement Mweya; E-mail: cmweya@nimr.or.tz 
et al., 1980). Moreover, records have shown that populations of $C x$. pipiens from the Maghreb are efficient experimental vectors of RVF (Amraoui et al., 2012) and in South Africa (Jupp \& Cornel, 1988). Despite a number of studies and records on RVF in Tanzania (Jost et al., 2010; Mohamed et al., 2010; Heinrich et al., 2012), there is inadequate information on mosquitoes incriminated as principal vectors for RVF virus persistence and transmission.

Lack of reliable techniques for sampling RVF vectors to determine abundance and distribution pattern associated with the disease epidemics could be among the factors hindering availability of information on RVF vectors in Tanzania. Studies in Kenya have identified important techniques for sampling RVF vectors (Tchouassi et al., 2012). Attempts to use such sampling techniques have been found to be useful in mosquito vectors for malaria and filariasis (Mboera et al., 2000a,b; Korgaonkar et al., 2008; Kitau et al., 2010). Inadequate sampling of potential RVF vectors may lead to under-reporting the role of mosquito in transmission and persistence of RVF virus during inter-epidemics period. The objective of this study was to compare sampling techniques for potential mosquito vectors of Rift Valley Fever virus in northern Tanzania.

\section{Materials and Methods}

\section{Study area}

The study was conducted from September to October 2012 in Ngorongoro district Tanzania (Figure 1). Ngorongoro District ( $\left.2^{\circ} \mathrm{S} 45^{\prime} 50.4^{\prime \prime}, 35^{\circ} \mathrm{E} 34^{\prime} \mathrm{O} 4.8^{\prime \prime}\right)$ is located in Arusha Region of northern Tanzania. According to the 2012 Tanzania National population and housing census, the population of the district was 174,278 (NBS, 2013). The district is considered as part of the Serengeti-Mara Ecosystem, which is defined by the limits of the annual wildlife migration. The district represents unique interaction between livestock, wildlife and human. Six villages, namely, Orgosorok, Soitsambu, Digodigo, Malambo, Sale and Pinyinyi were selected for the study.

\section{Mosquito collection}

Adult mosquito collections were made both outdoors and indoors. Indoor collections were made using CDC light traps. Un-baited light traps were set in four randomly selected houses in each village. Light traps were hung beside a sleeper who was provided with an untreated net as described by (Mboera et al., 1998). A person in the house was instructed on how to how to set and retrieve the trap at 17:0ohr and 07:00hr, respectively.

Outdoor mosquito collections were made using CDC light traps baited with carbon dioxide $\left(\mathrm{CO}_{2}\right)$ sachets and Mosquito Magnets (Cordless Liberty-Plus) alone or baited with Octenol. A Mosquito Magnet trap produces a continuous and odourless stream of $\mathrm{CO}_{2}$, warmth and moisture into the air (Kline, 2006; Kitau et al., 2010; Xue et al., 2010). Traps were set in proximity to potential breeding sites and under canopy in banana plantations and in proximity to animals sleeping areas. After every three hours, inspection was done on each trap to recover any trapped mosquito. Traps were set repeatedly in each area for three consecutive days and nights during the study period. All mosquitoes collected were sorted according to site of collection, type of trap, time of collection. Mosquito species were identified morphologically using specific keys (Huang, 2001). Each trap site was geo-referenced.

\section{Data analysis}

Data was entered into Microsoft Excel 2010 for basic descriptive statistics using pivot tables and then imported for analysis using the IBM Statistical Package for Social Sciences (SPSS) Version 19 and R statistical package. Mosquito were categorized by species, trapping techniques and time for 
collection. Comparison between the total numbers of mosquitoes caught per trapping technique was carried out by considering the differences in abundance and species composition. In order to obtain more realistic non-negative values for this non-normally distributed observations, this analysis was done using Poisson Generalized Linear Models (with a log link) at significance level of p-value < 0.05 (Demetrio, 2012).

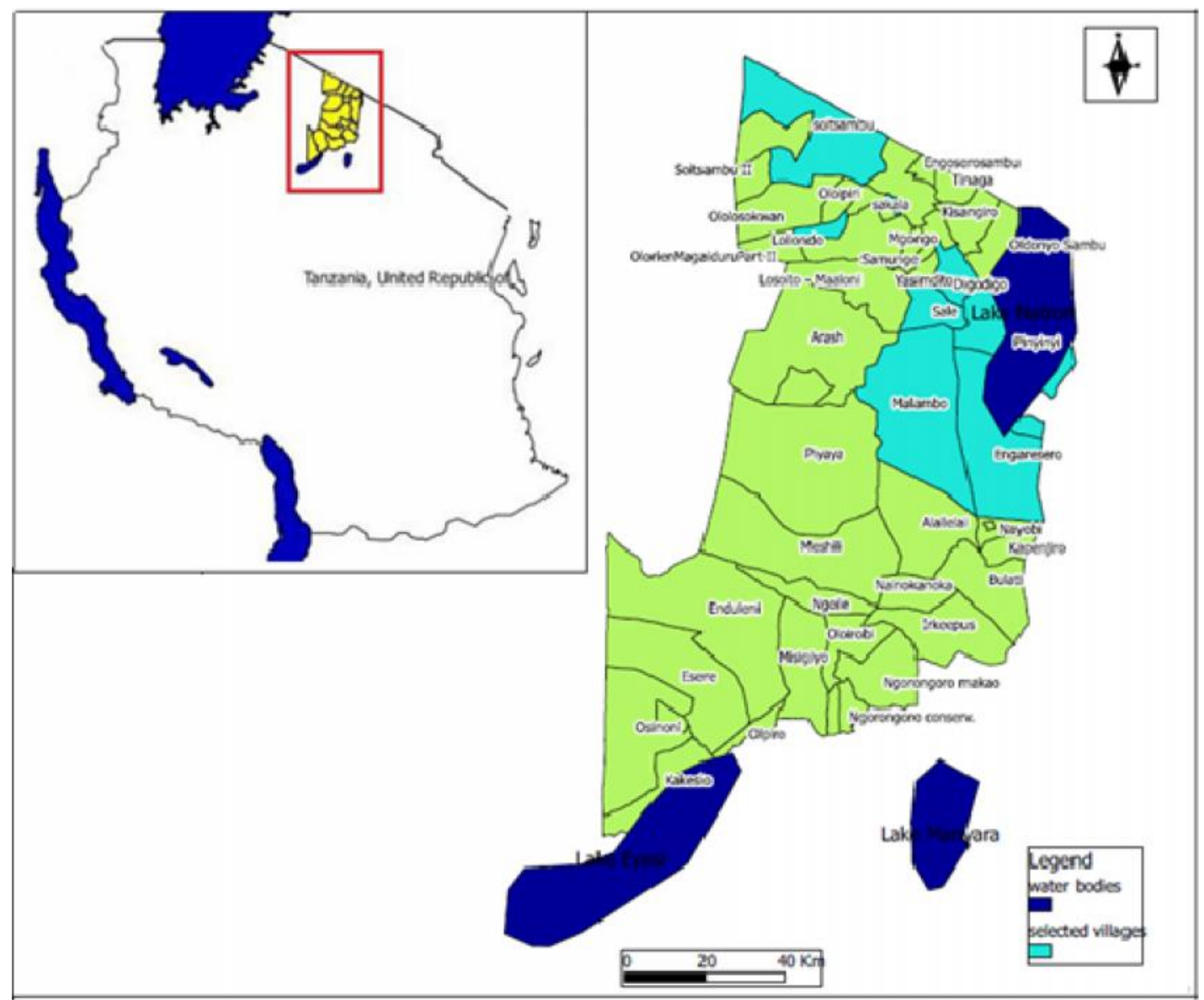

Figure 1: Map of Ngorongoro district indicating villages selected for the study

\section{Ethical considerations}

Ethical approval was sought from the Medical Research Coordinating Committee of the National Institute for Medical Research. Village leaders and house residents were asked for their consent before setting of mosquito traps in their houses or premises.

\section{Results}

\section{Mosquito abundance and trap efficiency}

A total of 1814 mosquitoes were collected, of which 40.68\% ( $=738)$ were collected by CDC light traps and $59.32 \%(\mathrm{~N}=1076)$ by Mosquito Magnet trapping technique. Of the collected mosquitoes, $12.46 \%(\mathrm{~N}=226)$ were Aedes aegypti and $87.54 \%(\mathrm{~N}=1588)$ Culex pipiens complex. More mosquitoes $(\mathrm{N}=660)$ were collected outdoors using octenol-baited Mosquito Magnets than indoor by un-baited $\mathrm{CDC}$ light traps ( $\mathrm{N}=537)$. Most of the Ae. aegypti mosquitoes were collected outdoor using Mosquito 
Magnets, 95\% ( $N=214)$ whereas Cx. pipiens complex were trapped both indoor using CDC light traps without attractant and outdoors using both $\mathrm{CDC}$ light traps baited with $\mathrm{CO}_{2}$ and Mosquito Magnet traps (Figure 2). Most Ae. aegypti mosquitoes were collected in Digodigo $(60.2 \%, \mathrm{~N}=136)$ and Pinyinyi (23.9\%, $\mathrm{N}=54)$ whereas more $C x$. pipiens were collected in Digodigo $(41.7 \%, \mathrm{~N}=667)$.

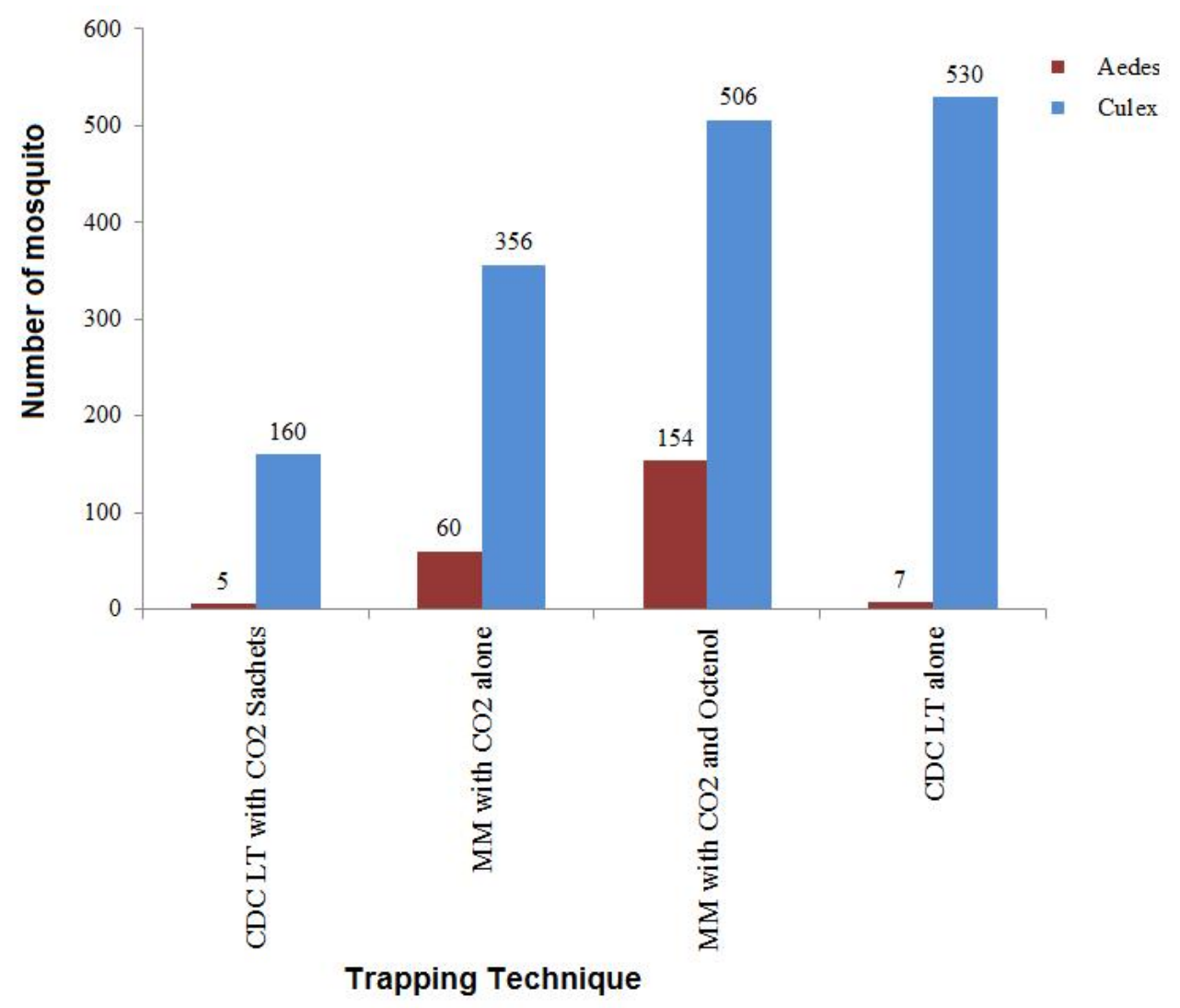

Figure 2: Number of Aedes aegypti and Culex pipiens mosquitoes trapped using Light traps (LT) and Mosquito Magnet (MM) traps

CDC light traps set indoor showed a low efficiency in catching Ae. aegypti with only seven mosquitoes captured indoors and five outdoors despite addition of $\mathrm{CO}_{2}$ as attractant. In contrast, outdoor trapping using Mosquito Magnets alone or baited with Octenol captured the largest proportion of $\mathrm{Cx}$. pipiens and Ae. aegypti (Figure 2). Most Ae. aegypti mosquitoes were captured in traps set under canopy in banana plantations and in proximity to animals sleeping area. In contrast, the number of $C_{x}$. pipiens trapped was similarly distributed both outdoors and indoors.

There were statistically significant differences in mosquito collection between different trapping methods. The indoor un-baited CDC light trap was more efficient in capturing $C x$. pipiens ( $p$ value $<0.05$ ). On the other hand, octenol-baited Mosquito Magnet set outdoor was more efficient to in collecting Ae. aegypti ( $\mathrm{p}$-value < 0.05). In this case both probabilities suggest strong evidence against the type of trap and attractant on the attractiveness to abundance of mosquito species. 


\section{Mosquito activity patterns}

Most Ae. aegypti mosquitoes were collected primarily during the first and last quarters of the day. This indicates activity of Ae. aegypti being a bimodal with one well-pronounced peak in the first three hours on the night (dawn) and another peak in the afternoon. Between these two peaks, mosquito activity was very low. $C x$ pipiens complex showed to be actively stable throughout the night, early evening and early morning then decreased markedly during the day time. In general, $C_{x}$ pipiens showed a more pronounced nocturnal activity than Ae. Aegypti (Figure 3).

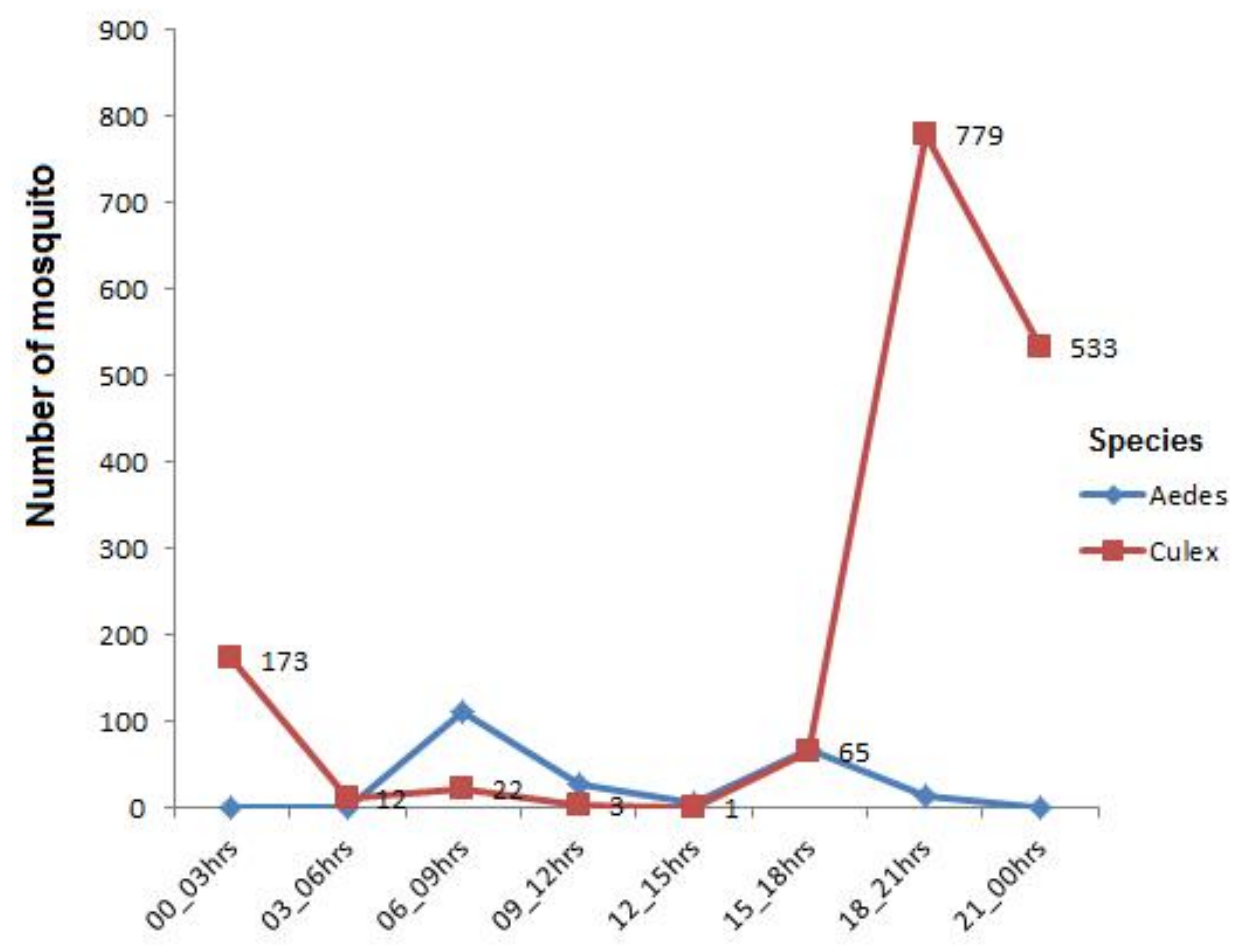

Collection time

Figure 3: Mosquito activity patterns based on mosquito collection time

\section{Discussion}

Efficient sampling of disease vectors provide important information on disease transmission and can provide more understanding on effective vectors for targeted control strategies (Krockel et al., 2006). Several mosquito sampling techniques are available have been mainly used to sample malaria and lymphatic filariasis vectors (Mboera et al., 1998; Mboera, 2005). The variation in mosquito activities observed in this study indicates that sampling of potential RVF vectors requires techniques that can maximize number of catches of both indoor and outdoor biting mosquitoes. Cx. pipiens complex indicated a similar activity pattern of being highly active during the evening to mid night with less or no activity during the day. This phenomenon has been observed in North Italy (Veronesi et al., 2012). The bimodal activity with peaks at dawn and afternoon, observed among Ae. aegypti in this study was similar to observations on Ae. albopictus in Macao, China. Similar results have been observed in the La Reunion Island (Delatte et al., 2010). This difference in catch between species, location and time provides important information for strategic vector sampling technique. 
The need for effective techniques for sampling potential RVF vectors is important as the role of mosquitoes in the maintenance and transmission of RVF virus in Tanzania is still not clear. Studies based on artificial flooding of grassland depressions in Kenya had led to identification of Ae. mcintoshi, Ae. ochraeus, Ae. dalzieli and Ae. vexans (Logan et al., 1990; Turell et al., 2008; Sang et al., 2010) as important vectors of RVF virus in the area. Ae. aegypti and Cx. pipiens complex have been observed in several RVF epidemic zones but their role has not been confirmed. However, the two species have been found to play a significant role in other epidemic zones such as Egypt (Meegan et al., 1980). Findings of this study have indicated that Mosquito Magnet trap is an efficient and practical tool for collecting Ae. aegypti. These traps have the advantage of collecting day biting outdoor mosquitoes because can easily be set and left in proximity with potential mosquito breeding areas.

In conclusion, because Ae. aegypti and Culex pipiens complex are important potential vectors of RVF, adequate sampling remain crucial in understanding of disease transmission during interepidemic periods. The results emphasize the possibility of using Mosquito Magnet traps in monitoring vector population dynamics in outdoor settings as are the best sampling tool for Ae. aegypti.

\section{Acknowledgements}

We acknowledge the District Executive Director, District Veterinary Officer and District Medical Officer of Ngorongoro for their support during the study. This study received financial support from the Tanzania Health Research Users Trust Fund under Capacity Development Strategy of the National Institute for Medical Research.

\section{Conflict of interest}

The authors declare no conflicts of interest

\section{References}

Amraoui, F., Krida, G., Bouattour, A., Rhim, A., Daaboub, J., Harrat, Z., Boubidi, S.C., Tijane, M., Sarih, M. \& Failloux, A.B. (2012) Culex pipiens, an experimental efficient vector of West Nile and Rift Valley fever viruses in the Maghreb region. PLoS One 7, e36757.

Becker, N., Zgomba, M., Petric, D. \& Ludwig, M. (1995) Comparison of carbon dioxide, octenol and a host-odour as mosquito attractants in the Upper Rhine Valley, Germany. Medical and Veterinary Entomology 9, 377-380.

Crabtree, M.B., Kent Crockett, R.J., Bird, B.H., Nichol, S.T., Erickson, B.R., Biggerstaff, B.J., Horiuchi, K. \& Miller, B.R. (2012) Infection and transmission of Rift Valley fever viruses lacking the NSs and/or NSm genes in mosquitoes: potential role for NSm in mosquito infection. PLoS Neglected Tropica Diseases 6, e1639.

Daubney, R., Hudson, J.R. \& Garnham, P.C. (1931) Enzootic Hepatitis or Rift Valley Fever. An undescribed virus disease of sheep, cattle and man from East Africa. Journal of Pathology and Bacteriology 34, 545-579

Davies, F.G. (1975) Observations on the epidemiology of Rift Valley fever in Kenya. Journal of Hygiene (London) 75, 219-230. 
Delatte, H., Desvars, A., Bouétard, A., Bord, S., Gimonneau, G., Vourch, G. \& Fontenille, D. (2010) Blood-Feeding Behavior of Aedes albopictus, a Vector of Chikungunya on La Réunion. VectorBorne and Zoonotic Diseases 10, 249-258.

Demetrio, C.G.B. (2012) Introduction to General and Generalized Linear Models by Madsen, H. and Tyregod, P. Biometrics 68, 327.

Diallo, M., Lochouarn, L., Ba, K., Sall, A.A., Mondo, M., Girault, L. \& Mathiot, C. (2000) First isolation of the Rift Valley fever virus from Culex poicilipes (Diptera: Culicidae) in nature. American Journal of Tropical Medicine and Hygiene 62, 702-704.

EFSA (2013) Scientific Opinion on Rift Valley fever; EFSA Panel on Animal Health and Welfare (AHAW). EFSA Journal 11, 3180.

Gerdes,G.H. (2002) Rift valley fever. Veterinary Clinician of North American Food and Animal Practice $18,549-555$.

Heinrich, N., Saathoff, E., Weller, N., Clowes, P., Kroidl, I., Ntinginya, E., Machibya, H., Maboko, L., Loscher, T., Dobler, G. \& Hoelscher, M. (2012) High seroprevalence of Rift Valley fever and evidence for endemic circulation in Mbeya region, Tanzania, in a cross-sectional study. PLoS Neglected Tropical Diseases 6, e1557.

Huang,Y.M. (2001) A pictorial key for the identification of the subfamilies of Culicidae, genera of Culicinae, and subgenera of Aedes mosquitoes of the Afrotropical Region (Diptera: Culicidae). Proceedings of the Entomological Society of Washington 103.

Jost,C.C., Nzietchueng,S., Kihu,S., Bett,B., Njogu,G., Swai,E.S. \& Mariner,J.C. (2010) Epidemiological assessment of the Rift Valley fever outbreak in Kenya and Tanzania in 2006 and 2007. American Journal of Tropical Medicine and Hygiene 83, 65-72.

Jupp,P.G. \& Cornel,A.J. (1988) Vector competence tests with Rift Valley fever virus and five South African species of mosquito. Journal of American Mosquito Control Association 4, 4-8.

Kitau, J., Pates, H., Rwegoshora, T.R., Rwegoshora, D., Matowo, J., Kweka, E.J., Mosha, F.W., McKenzie, K. \& Magesa, S.M. (2010) The effect of Mosquito Magnet Liberty Plus trap on the human mosquito biting rate under semi-field conditions. Journal of American Mosquito Control Association 26, 287-294.

Kline, D.L. (2006) Traps and trapping techniques for adult mosquito control. Journal of American Mosquito Control Association 22, 490-496.

Korgaonkar, N.S., Kumar, A., Yadav, R.S., Kabadi, D. \& Dash, A.P. (2008) Sampling of adult mosquito vectors with Mosquito Magnet Pro in Panaji, Goa, India. Journal of American Mosquito Control Association 24, 604-607.

Krockel, U., Rose, A., Eiras, A.E. \& Geier, M. (2006) New tools for surveillance of adult yellow fever mosquitoes: comparison of trap catches with human landing rates in an urban environment. Journal of American Mosquito Control Association 22, 229-238.

Linthicum, K.J., Anyamba, A., Tucker, C.J., Kelley, P.W., Myers, M.F. \& Peters, C.J. (1999) Climate and satellite indicators to forecast Rift Valley fever epidemics in Kenya. Science 285, 397-400.

Logan, T.M., Linthicum, K.J., Thande, P.C., Wagateh, J.N., Nelson, G.O. \& Roberts, C.R. (1991) Egg hatching of Aedes mosquitoes during successive floodings in a Rift Valley fever endemic area in Kenya. Journal of American Mosquito Control Association 7, 109-112.

Logan, T.M., Linthicum, K.J., Wagateh, J.N., Thande, P.C., Kamau, C.W. \& Roberts, C.R. (1990) Pretreatment of floodwater Aedes habitats (dambos) in Kenya with a sustained-release formulation of methoprene. Journal of American Mosquito Control Association 6, 736-738.

Mboera, L.E.G. (2005) Sampling techniques for adult Afrotropical malaria vectors and their reliability in the estimation of entomological inoculation rate. Tanzania Health Research Bulletin 7, 117124. 
Mboera, L.E.G., Kihonda, J., Braks, M.A. \& Knols, B.G. (1998) Short report: Influence of centers for disease control light trap position, relative to a human-baited bed net, on catches of Anopheles gambiae and Culex quinquefasciatus in Tanzania. American Journal of Tropical Medicine and Hygiene 59, 595-596.

Mboera, L.E.G., Takken, W. \& Sambu, E.Z. (2000a) The response of Culex quinquefasciatus (Diptera: culicidae) to traps baited with carbon dioxide, 1-octen-3-ol, acetone, butyric acid and human foot odour in Tanzania. Bulletin of Entomological Research 90, 155-159.

Mboera, L.E.G., Knols, B.G.J., Braks, M.A.H. \& Takken, W. (2000b) Comparison of carbon dioxidebaited trapping systems for sampling outdoor mosquito populations in Tanzania. Medical and Veterinary Entomology 14, 257-263.

Meegan, J.M., Khalil, G.M., Hoogstraal, H. \& Adham, F.K. (1980) Experimental transmission and field isolation studies implicating Culex pipiens as a vector of Rift Valley fever virus in Egypt. American Journal of Tropical Medicine and Hygiene 29, 1405-1410.

Mohamed, M., Mosha, F., Mghamba, J., Zaki, S.R., Shieh, W.J., Paweska, J., Omulo, S., Gikundi, S., Mmbuji, P., Bloland, P., Zeidner, N., Kalinga, R., Breiman, R.F. \& Njenga, M.K. (2010) Epidemiologic and clinical aspects of a Rift Valley fever outbreak in humans in Tanzania, 2007. American Journal of Tropical Medicine and Hygiene 83, 22-27.

Moutailler, S., Krida, G., Schaffner, F., Vazeille, M. \& Failloux, A.B. (2008) Potential vectors of Rift Valley fever virus in the Mediterranean region. Vector Borne and Zoonotic Diseases 8, 749-753.

NBS (2013) Tanzania National Population and Housing Census 2012. General Report, National Bureau of Statistics. Dar es Salaam. Tanzania.

Nguku, P.M., Sharif, S.K., Mutonga, D., Amwayi, S., Omolo, J., Mohammed, O., Farnon, E.C., Gould, L.H., Lederman, E., Rao, C., Sang, R., Schnabel, D., Feikin, D.R., Hightower, A., Njenga, M.K. \& Breiman, R.F. (2010) An investigation of a major outbreak of Rift Valley fever in Kenya: 20062007. American Journal of Tropical Medicine and Hygiene 83, 5-13.

Romoser, W.S., Oviedo, M.N., Lerdthusnee, K., Patrican, L.A., Turell, M.J., Dohm, D.J., Linthicum, K.J. \& Bailey, C.L. (2011) Rift Valley fever virus-infected mosquito ova and associated pathology: possible implications for endemic maintenance. Dove Journal Press 121-127.

Sang, R., Kioko, E., Lutomiah, J., Warigia, M., Ochieng, C., O'Guinn, M., Lee, J.S., Koka, H., Godsey, M., Hoel, D., Hanafi, H., Miller, B., Schnabel, D., Breiman, R.F. \& Richardson, J. (2010) Rift Valley fever virus epidemic in Kenya, 2006/2007: the entomologic investigations. American Journal of Tropical Medicine and Hygiene 83, 28-37.

Tchouassi, D.P., Sang, R., Sole, C.L., Bastos, A.D., Cohnstaedt, L.W. \& Torto, B. (2012) Trapping of Rift Valley Fever (RVF) vectors using light emitting diode (LED) CDC traps in two arboviral disease hot spots in Kenya. Parasites \& Vectors 5, 94.

Turell, M.J., Linthicum, K.J., Patrican, L.A., Davies, F.G., Kairo, A. \& Bailey, C.L. (2008) Vector competence of selected African mosquito (Diptera: Culicidae) species for Rift Valley fever virus. Journal of Medical Entomology 45, 102-108.

Veronesi, R., Gentile, G., Carrieri, M., Maccagnani, B., Stermieri, L. \& Bellini, R. (2012) Seasonal pattern of daily activity of Aedes caspius, Aedes detritus, Culex modestus, and Culex pipiens in the Po Delta of northern Italy and significance for vector-borne disease risk assessment. Journal of Vector Ecology 37, 49-61.

Xue, R.D., Qualls,W.A., Kline,D.L. \& Zhao,T.Y. (2010) Evaluation of lurex 3, octenol, and CO2 sachet as baits in Mosquito Magnet Pro traps against floodwater mosquitoes. Journal of American Mosquito Control Association 26, 344-345. 